\section{Birth weight and the risk of depressive disorder}

\section{in late life}

\author{
CHRISTOPHER THOMPSON, HOLLY SYDDALL, IAN RODIN, CLIVE OSMOND \\ and DAVID J. P. BARKER
}

In the past decade a series of studies has shown that coronary heart disease, hypercholesterolaemia, hypertension, stroke and non-insulin-dependent diabetes mellitus (NIDDM) have their origins in foetal life (Barker et al, 1989; Barker, 1998). Low birth weight in singletons born at term and a low growth rate in early infancy leading to low weight at 1 year are both implicated in these conditions. These studies have been replicated in many parts of the world (Forsen et al, 1997) and show that the associations are independent of social class or adult lifestyle. A few studies have suggested that in monozygotic twins discordant for hypertension (Poulter et al, 1999) and diabetes (Poulsen et al, 1997) the lighter baby is most likely to develop the illness, demonstrating that these effects may operate independently of genetic vulnerability.

The growth of a foetus is determined mainly by the intra-uterine environment and is limited by the nutrients and oxygen it receives (Morton, 1955; McCance \& Widdowson, 1974; Barker, 1998). Individual organs differ in the time of maximum growth rates and therefore have different critical times in their development. Male foetuses have more rapid growth trajectories than females and therefore are more vulnerable to impaired nutrition (Barker, 1998).

\section{Hormonal programming}

The relationship between undernutrition and later disease is mediated by persisting changes to the internal environment of the individual. In particular there are longlasting effects known as 'hormonal programming' in which the plasma levels of hormones or the set points of neuroendocrine systems are altered permanently. These have been shown to occur in the hypothalamic-pituitary-adrenal (HPA), growth-hormone, thyroxine and insulin axes. There is a clear association between depressive disorder and cardiovascular disease in community samples (Vaillant, 1998) and this relationship is still present after controlling for smoking (Anda et al, 1993). The association is stronger in men than in women (Hippisley-Cox et al, 1998). The cause of the association is unknown and in some cases it may be simply a reaction to the physical disability. Other commentators have suggested that depression itself may induce physical disease, possibly by increasing levels of stress hormones (Dinan, 1998). Another possibility that has not been discussed previously is that both depression and cardiovascular disease may share a common vulnerability factor in foetal life.

\section{Relevance to depression}

The causes of depression are incompletely understood. Adverse life events often are the proximal cause of a depressive illness (Murphy, 1982) but act selectively on vulnerable individuals (Kendler et al, 1999). Although a genetic predisposition usually is postulated, particularly in more severe forms, no individual genes have been identified reliably as yet. Some estimates place the heritability at only $36-44 \%$ in women and rather less in men (Bierut et $a l, 1999)$. Thus, there are reasons to doubt an overwhelming effect of genetic influences on the predisposition to depression and to anticipate other constitutional factors, particularly in men, for whom the heritability appears to be lower.

One such constitutional factor may be foetal undernutrition, leading to low birth weight. This possibility is indicated by two studies of the Dutch Hunger Winter (Brown et al, 1995, 2000) in which a second-trimester exposure to famine conditions was associated with an increased risk of admission for affective psychosis in later life. These studies had the limitation of relying on hospital admissions for case identification, which may have introduced a nosocomial artefact.

In a previous study, we have used death certificates to identify cases of suicide in a cohort born during 1911-1930 in Hertfordshire, England (Barker et al, 1995). The standardised mortality ratio for suicide was higher in babies who were lighter at 1 year. Although this study supported an association between low growth rates and depression, it only did so circumstantially, because the relationship between depressive disorder and 
suicide is not invariable. We have therefore tested the hypothesis further by determining the rates of depressive disorder among surviving members of the Hertfordshire birth cohort.

\section{METHOD}

\section{Subjects}

The study population has been described previously (Osmond et al, 1993). All births in the English county of Hertfordshire from 1911 onwards were notified to the county medical officer of health by the attending midwife. Health visitors saw the babies periodically through infancy and recorded the method of feeding, date of birth, birth weight, name, address and paternal occupation, and wrote general comments on the babies' health and well-being. At 1 year the babies were weighed again. In the early 1990s the National Health Service Central Register (NHSCR) was used to trace all singleton births that had survived until 5 years of age.

We traced 10141 of the boys and 5585 of the girls. Previously we had studied growth in infancy in relation to cardiovascular disease and to Helicobacter pylori infection in subsamples of 631 men and 389 women born during 1920-1930 and still living in the east or north-west districts of the county, and these formed the population for the current study. They comprised $5 \%$ of all men and women born in east and north-west Hertfordshire during $1920-1930$ and $42 \%$ of all such births known to be still living in the county (Fall et al, 1997). As part of the current study we wrote to these 1020 subjects, asking them to take part in a study looking at the effects of early development on 'how stress affects people'.

\section{Procedures}

The subjects were interviewed in their home by a research nurse who had met them already in the course of previous studies. The nurses were unaware of the data on the subjects' birth records. They also asked about known risk factors for depression in the elderly, including social isolation (Green et al, 1992), bereavement (Beekman et al, 2001) and illness (Prince et al, 1998).

Two standard measures were used to assess current depression. The first was the 15 -item version of the self-administered Geriatric Depression Scale (GDS), a score of 5 or more indicating a probable case of depression (Almeida \& Almeida, 1999). This threshold has a sensitivity of $92.7 \%$ and a specificity of $62.5 \%$ using the ICD10 (World Health Organization, 1992) depressive episode as a gold standard. The second was the Geriatric Mental State B version (GMS), a semi-structured interview adapted from the Present State Examination (McWilliam et al, 1988). A score of 3 or more indicates depressive disorder and the assessment distinguishes between psychotic depression, neurotic depression and generalised anxiety disorder.

The research nurses attended a 5-day GMS training course and were supervised regularly throughout the study. Interrater reliability for the GMS was assessed by rating of videos before and during the study. As an additional measure of quality control, the GMS was repeated within 1 week by I.R. on $42(4.8 \%)$ subjects selected at random.

Because our hypothesis was formed from the recognition of the comorbidity of depression and coronary heart disease, it was important to show that any association between low birth weight and depression was not mediated solely by this effect. For each subject the results of the Rose questionnaire (a measure of disability due to ischaemic heart disease; Rose \& Blackburn, 1968) and electrocardiogram evidence of cardiac ischaemia were available from previous studies and were used to adjust for coronary heart disease in the analyses.

\section{Statistical analysis}

Three definitions of depression were used in the analyses: depression according to either the GMS or GDS definition; GDS score above threshold; and a GDS diagnosis of depression (any category). The first definition was the primary analysis of the study because there was no a priori reason to expect an association to be restricted to any given diagnostic sub-category of depression. Secondary analyses examined the relationships between birth weight, weight at 1 year and individual definitions of depression.

Logistic regression models were used to analyse the association between depression and birth weight and weight at 1 year while adjusting for known risk factors of depression. Analyses were carried out for men and women separately. Summary tables of these associations used the same divisions into weight categories as in previous analyses
(Fall et al, 1997). Continuous measures of birth weight and weight at 1 year were entered in the logistic regression models. All analyses were carried out using STATA, release 5 (StataCorp, 1997). The effect of birth weight was adjusted for weight at 1 year, as has been the case in previous analyses of the effects in other diseases. Weight at 1 year is influenced less by the intra-uterine environment and so corrects to some degree for catch-up growth to the adult size.

\section{RESULTS}

Of the 1020 subjects 882 agreed to participate. Others refused to participate, had died, moved away or were lost to contact. There were 542 men (mean age 68 years) and 340 women (mean age 68 years).

All subjects completed the GDS and 74 (42 men and 32 women) thereby were classified as having depression. A total of 867 subjects completed the GMS. Twelve subjects (five men and seven women) were classified as having psychotic depression; 54 (25 men and 29 women) had neurotic depression; and 14 had generalised anxiety disorder, of whom 12 also met the criteria for a depression diagnosis and therefore were included as 'depressed' in the analysis. The two with pure anxiety were classified as 'not depressed'.

Altogether, 113 subjects $(57$ men and 56 women) had depression according to either of the assessments and were treated as cases in the primary analysis. The prevalence of depression, so defined, was $11 \%$ in men and $16 \%$ in women. Twenty-four subjects (12 men and 12 women) had depression according to both assessments.

\section{Known risk factors for depression}

Twenty-four per cent of the men were in social classes I and II; $10 \%$ were in III non-manual, $45 \%$ were in III manual and $22 \%$ were in IV and V. The corresponding figures for women were $25 \%, 20 \%, 31 \%$ and $25 \%$.

Table 1 shows that by using social class as a trend variable the prevalence of any depression (GMS or GDS) was, as expected, higher in the lower social classes. There was a similar trend with social class at birth. Both current social class and social class at birth made independent contributions to the risk of depression. In both males and females the risk of depression was increased also by bereavement in the 
Table I Odds ratios for depression according to known risk factors in late life

\begin{tabular}{|c|c|c|c|c|c|c|c|c|c|}
\hline \multirow[t]{2}{*}{ Risk factor } & & \multicolumn{4}{|c|}{ Men } & \multicolumn{4}{|c|}{ Women } \\
\hline & & $n$ & $\begin{array}{c}\text { No. positive } \\
\text { (\%) }\end{array}$ & $\begin{array}{c}\text { OR } \\
(95 \% \mathrm{Cl})\end{array}$ & $\begin{array}{c}\text { Adjusted } \\
\text { OR }(95 \% \mathrm{Cl})^{2}\end{array}$ & $n$ & $\begin{array}{c}\text { No. positive } \\
\text { (\%) }\end{array}$ & $\begin{array}{c}\text { OR } \\
(95 \% \mathrm{Cl})\end{array}$ & $\begin{array}{c}\text { Adjusted } \\
\text { OR }(95 \% \mathrm{Cl})^{2}\end{array}$ \\
\hline Current social class' & & 524 & - & $1.3(1.0-1.6)$ & $1.3(1.0-1.7)$ & 334 & - & $1.3(1.1-1.7)$ & $1.3(1.0-1.6)$ \\
\hline Social class at birth' & & 497 & - & $1.3(1.0-1.8)$ & $1.2(0.9-1.6)$ & 320 & - & $1.3(1.0-1.8)$ & $1.2(0.9-1.7)$ \\
\hline \multirow[t]{2}{*}{ Bereavement in past year } & No & 433 & $44(10.2)$ & & & 265 & $39(14.7)$ & & \\
\hline & Yes & 94 & $13(13.8)$ & $1.4(0.7-2.8)$ & I.I (0.5-2.5) & 75 & $17(22.7)$ & $1.7(0.9-3.2)$ & $1.7(0.8-3.5)$ \\
\hline \multirow[t]{2}{*}{ Living alone } & No & 455 & $48(10.6)$ & & & 231 & $32(13.9)$ & & \\
\hline & Yes & 72 & $9(12.5)$ & $1.2(0.6-2.6)$ & I.I (0.4-2.9) & 109 & $24(22.0)$ & $1.8(1.0-3.2)$ & $1.9(0.9-3.9)$ \\
\hline \multirow[t]{2}{*}{ Social contact $<$ once daily } & No & 486 & $53(10.9)$ & & & 300 & $47(15.7)$ & & \\
\hline & Yes & 41 & $4(9.8)$ & $0.9(0.3-2.6)$ & $0.6(0.1-2.5)$ & 40 & $9(22.5)$ & $1.6(0.7-3.5)$ & $1.0(0.4-2.8)$ \\
\hline \multirow[t]{2}{*}{ Illness causing pain } & No & 353 & $25(7.1)$ & & & 205 & $24(11.7)$ & & \\
\hline & Yes & 174 & $32(18.4)$ & $3.0(1.7-5.2)$ & $1.9(1.0-3.6)$ & 135 & $32(23.7)$ & $2.3(1.3-4.2)$ & $2 . I(1 . I-4.1)$ \\
\hline \multirow[t]{2}{*}{ Illness preventing activity } & No & 391 & $25(6.4)$ & & & 257 & $32(12.5)$ & & \\
\hline & Yes & 136 & $32(23.5)$ & $4.5(2.6-7.9)$ & $4.4(2.3-8.3)$ & 83 & 24 (28.9) & $2.9(1.6-5.2)$ & 2.1 (I.I-4.I) \\
\hline
\end{tabular}

I. Social class at birth and current social class were each treated as trend variables (coded I=social class $\mathrm{I}$, through to $6=$ social class $\mathrm{V}$ ). The odds ratios presented for these variables are per unit change in social class (in the non-manual direction).

2. Mutually adjusted odds ratio: 495 valid observations for men and 315 valid observations for women.

previous year, living alone, having an illness causing pain or having an illness preventing activity. In women, but not men, depression was associated also with social isolation. The adjusted odds ratios in Table 1 show that all of these known risk factors for depression exerted an independent effect, although only the odds ratios for social class and illness were statistically significant. All of the risk factors in Table 1 were adjusted for in subsequent analyses, whether or not they were statistically significant.

\section{Associations with birth weight, weight at I year and infant feeding}

Table 2 shows that among men but not women the odds ratios for depression fell with increasing birth weight. Adjusting for weight at 1 year increased this effect. Relative to those born over 8.5 pounds, the odds ratios rose from 2.8 (95\% CI 0.9-8.9) for those weighing $7.5-8.5 \mathrm{lb}$, to $3.2(95 \% \mathrm{CI}$ $1.0-10.5)$ for those weighing $6.5-7.5 \mathrm{lb}$, to 3.5 (95\% CI 1.0-12.8) for those weighing up to $6.5 \mathrm{lb}$ (for the trend $P=0.007$ ). For the small group of men who weighed up to $5.5 \mathrm{lb}$ at birth compared with those who weighed more than $9.5 \mathrm{lb}$ the odds ratio was $18.5 \quad(95 \%$ CI $4.0-86.1$; $P<0.0001)$. In a simultaneous analysis the trend in the risk of depression with birth weight $(P=0.01)$ was independent of the trend with social class at birth $(P=0.07)$

In view of the hybrid definition of depression used in the primary analysis the two definitions were entered separately into the same analysis described above. None of these analyses gave significant results in the females. The GMS definition yielded an odds ratio between birth weight (adjusted for weight at 1 year) and depression of $0.72(P=0.05)$, lighter male babies being at higher risk. There was also a significant association between greater weight at 1 year (adjusted for birth weight) and increased risk of depression $(\mathrm{OR}=1.18$, $P=0.05)$. The GDS gave similar trends but these were not significant (adjusted OR for birth weight $=0.79, P=0.17$; adjusted OR for weight at 1 year $=1.08, P=0.36$ ).

There were 65 men and 37 women with definite coronary heart disease in the primary analysis. After adjusting for coronary heart disease the associations between birth weight and depression in men remained and became more significant. Relative to those born over $8.5 \mathrm{lb}$ the odds ratios for birth weight, adjusted for weight at 1 year, were $3.0(95 \%$ CI $0.9-9.8)$ for those $7.5-8.5 \mathrm{lb}, 3.1$ (95\% CI 0.9-10.4), for those $6.5-7.5 \mathrm{lb}$ and 4.1 (95\% CI 1.1-15.2) for those under $6.5 \mathrm{lb}$ (for the trend $P=0.005$ ). The association with weight at 1 year, adjusted for coronary heart disease as well as birth weight, was not significant, and the associations in females remained nonsignificant.

We then removed the subjects with definite coronary heart disease and repeated the primary analysis on the remaining 428 men and 274 women. Once again the odds ratios increased in value as the birth weight declined (overall $P<0.004$ ).

In contrast to the trend with birth weight, odds ratios rose with increasing weight at 1 year, although this trend was statistically significant only in the GMS data adjusted for birth weight and including those with coronary heart disease. The highest risk was found among men who had low birth weight but higher weight at 1 year, whereas the lowest risk was among men who had high birth weight, but lower weight at 1 year. We also examined the method of infant feeding because such data were available from the contemporary records. Of the subjects 605 were exclusively breast-fed, 221 were breast- and bottle-fed before weaning and 41 were exclusively bottlefed. There was no relationship to the risk of depression.

\section{DISCUSSION}

\section{What does this study add to previous findings?}

These results place late-life depression in the same category of illness as cardiovascular 
Table 2 Odds ratios for depression according to birthweight and weight at I year

\begin{tabular}{|c|c|c|c|c|c|c|c|c|}
\hline & \multicolumn{4}{|c|}{ Men } & \multicolumn{4}{|c|}{ Women } \\
\hline & $n$ & $\begin{array}{c}\text { \% With } \\
\text { depression }\end{array}$ & $\begin{array}{c}\text { OR } \\
(95 \% \mathrm{Cl})\end{array}$ & $\begin{array}{c}\text { Adjusted OR } \\
(95 \% \mathrm{Cl})\end{array}$ & $n$ & $\begin{array}{c}\text { \% With } \\
\text { depression }\end{array}$ & $\begin{array}{c}\text { OR } \\
(95 \% \mathrm{Cl})\end{array}$ & $\begin{array}{c}\text { Adjusted OR } \\
(95 \% \mathrm{Cl})\end{array}$ \\
\hline \multicolumn{9}{|c|}{ Birthweight (Ib) } \\
\hline$<6.5$ & 76 & 13.2 & $3.0(0.9-10.6)$ & $3.5(1.0-12.8)^{1}$ & 76 & I7.I & $0.7(0.2-1.9)$ & $0.7(0.2-2.2)^{\prime}$ \\
\hline $6.5-7.5$ & 149 & 12.1 & $2.7(0.9-8.7)$ & $3.2(1.0-10.5)^{1}$ & 99 & 16.2 & $0.8(0.3-2.2)$ & $0.9(0.3-2.4)^{1}$ \\
\hline $7.5-8.5$ & 176 & 11.4 & $2.5(0.8-7.9)$ & $2.8(0.9-8.9)^{\prime}$ & 95 & 15.8 & $0.7(0.3-1.8)$ & $0.7(0.3-1.8)^{\prime}$ \\
\hline$>8.5$ & 94 & 4.3 & $\begin{array}{l}1.0 \\
\quad(P=0.02)\end{array}$ & $\begin{array}{l}1.0 \\
\quad(P=0.007)\end{array}$ & 45 & 20.0 & $\begin{array}{l}1.0 \\
\quad(P=0.19)\end{array}$ & $\begin{array}{l}1.0 \\
\quad(P=0.32)\end{array}$ \\
\hline \multicolumn{9}{|c|}{ Weight at I year (lb) } \\
\hline$<20.5$ & 94 & 10.6 & 1.0 & 1.0 & 125 & 16.8 & 1.0 & 1.0 \\
\hline $20.5-22.5$ & 160 & 11.3 & I.2(0.5-2.9) & $1.3(0.5-3.1)^{2}$ & 110 & 15.5 & $0.9(0.4-1.8)$ & $0.8(0.4-1.8)^{2}$ \\
\hline $22.5-24.5$ & 132 & 8.3 & $0.9(0.3-2.3)$ & $1.0(0.4-2.6)^{2}$ & 62 & 17.7 & I.3 (0.5-3.0) & $1.2(0.5-3.1)^{2}$ \\
\hline$>24.5$ & 109 & 11.9 & $\begin{array}{c}1.6(0.6-4.2) \\
(P=0.37)\end{array}$ & $\begin{array}{c}2.1(0.8-5.6)^{2} \\
\quad(P=0.10)\end{array}$ & 18 & 22.2 & $\begin{array}{c}\text { I.3 (0.4-4.9) } \\
(P=0.33)\end{array}$ & $\begin{array}{c}1.3(0.3-5.0)^{2} \\
(P=0.65)\end{array}$ \\
\hline
\end{tabular}

Odds ratios are given relative to the heaviest category for birth weight and the lightest category for weight at I year. All are adjusted for all the (significant and non-significant) risk factors shown in Table I. The $P$ value is given for the trend in odds ratios across all categories. Depression was defined using the hybrid Geriatric Mental State or Geriatric Depression Scale definition.

I. Adjusted for weight at I year.

2. Adjusted for weight at birth.

disease, NIDDM and hypertension, the vulnerability to which begins in foetal life. The findings explain some of the comorbidity between depression and cardiovascular disease and diabetes (Popkin et al, 1988) because they appear to be related to a common vulnerability factor. They add to our previous study of suicide in the same cohort (Barker et al, 1995) and to the studies of affective psychosis after the Dutch Hunger Winter (Brown et al, 1995, 2000). Sacker et al (1995) also found lower birth weight in patients admitted with affective psychosis who were part of the British Perinatal Mortality Survey of 1958. Unlike these previous samples, the definition of depression in our study was not dependent upon admission to hospital or on the accuracy of hospital records, but was made on the basis of a self-rating scale or a semistructured interview of the survivors of a birth cohort. In addition, unlike the Dutch sample, the cohort was born in peace time and had not been subjected to unusual or extreme conditions.

The findings demonstrate that, among men, low birth weight increases the risk of depression in late life, almost 70 years later, and does so independently of social class at birth, current social class and the other known risk factors of social isolation, recent bereavement and illness. Considering the high levels of comorbidity between depression and coronary heart disease, it is particularly important that the associations remained after both adjusting for and excluding those with coronary heart disease.

In addition to affective disorders, low birth weight has been associated with schizophrenia in adults (Rifkin et al, 1994; Sacker et al, 1995; Susser et al, 1996; Jones et al, 1998). Among those with schizophrenia and bipolar disorder, patients with poorer premorbid functioning had been born at the lower weight (Foerster et al, 1991; Cannon et al, 1997).

It is important to differentiate between very-low-birth-weight premature babies, who often need special baby care, and the effect of birth weight at term expressed as a continuous variable, as in our results. However, such very-low-birth-weight groups also appear to show a range of neurodevelopmental abnormalities (Breslau, 1995), including attention-deficit hyperactivity disorder and intellectual deficits.

\section{What are the limitations of our findings?}

Our study used a hybrid definition of depression in the primary analysis, consisting of a high score on a rating scale and/or an interview-based diagnosis. Although not as ideal as using a single definition, it is unlikely that this hybrid definition affected the results, for two reasons: they depend on trends within the sample; and the association was found also in the secondary analysis of the interview-based diagnostic variable (GMS) alone. Using the primary outcome variable, 113 subjects $(21 \%)$ were rated as having depression, reflecting the inclusiveness of the GMS system. The use of this broad definition in our study suggests that the association between birth weight and depression was not confined to severe or psychotic cases such as those that have been studied previously (Brown et al, 1995, 2000).

Our subjects were interviewed only once at a late stage in life and the absence of life-time histories of depression would have introduced a conservative bias into the current study. Depression at younger ages, although different in some respects from late-life depression (National Institutes of Health, 1992), also is known to be a risk factor for depression in the elderly (Beekman et al, 2001) and our findings therefore might be expected to apply to depression in younger adults. However, more information is needed for life-time histories, derived for example from medical records and by studying a younger cohort, before this can be confirmed. Such a study currently is under way.

\section{Interpretation of the findings}

It has been known for many years that foetal growth is determined by the intra-uterine 
environment (McCance \& Widdowson, 1974), specifically the ability of the mother to deliver nutrients. We postulate that male foetuses that are nutritionally stressed and grow slowly in utero are more likely to become depressed in adulthood. Female foetuses grow more slowly than males and therefore are less vulnerable at critical periods of development (Forsen et al, 1997).

\section{Possible confounding variables}

Genetic influences could confound our interpretation only if mothers with depression have low-birth-weight babies and (separately) confer a genetic vulnerability to depression on their offspring. An association between postnatal depression and low birth weight has recently been reported (Bergant et al, 1999) but this was accounted for by obstetric complications. A predominantly genetic explanation would have been expected to produce a larger effect in female than in male offspring (Bierut et al, 1999). It is noteworthy that not only our study but also the studies of the Dutch Hunger Winter found the effect to be greater in males than in females (Brown et al, 1995, 2000).

It is equally unlikely that social factors mediate the association because by the age of 1 year the affected individuals had caught up in their growth. Nevertheless, even though we controlled for social class at birth and at interview, it remains possible that the effects of socio-economic deprivation are not accounted for entirely by the employment descriptions that we used. If the risk of living in deprivation continued throughout life, and such deprivation caused low birth weight and independently caused depression in old age, then it is possible that the results were an artefact of socio-economic deprivation. However, it is possible also that the biological effects of socio-economic deprivation on foetal growth and on other prenatal biological variables partially mediate its effect on depression. Some of the mechanisms by which this may arise will be discussed now.

\section{Candidate mechanisms}

There are several mechanisms by which undernutrition of the foetus might cause permanent changes that increase later vulnerability to depression. Foremost among these is programming of the HPA axis. Small male babies have increased urinary adrenal androgen and glucocorticoid metabolite excretion at age 9 years (Clark et al, 1996) and higher fasting cortisol concentrations as adults (Philips et al, 1998). Raised plasma cortisol level is the most consistently demonstrated biological abnormality in primary depressive disorder (Nemeroff $e t$ al, 1984; Murphy, 1991; Lopez et al, 1998). The growth hormone axis is another candidate. Median 24-h plasma growth hormone concentrations are related to weight at 1 year (Fall et al, 1998), and in depression the control of growth hormone secretion is known to be disturbed. For example, growth hormone secretion in response to both clonidine (Checkley et al, 1984) and slow wave sleep (Sakkas et al, 1998 ) is reduced in patients with depression. Thyroid function also may be set during foetal growth and infant feeding (Philips et al, 1993) and reduced plasma thyrotropin levels coupled with impaired response to thyrotropin-releasing hormone (Schule et al, 1997) are associated with depression (Oomen et al, 1996).

Although the brain is relatively protected during intra-uterine life, foetal undernutrition at critical periods can have neurodevelopmental effects - reducing cellular growth (Winick et al, 1972), later IQ (Davies \& Stewart, 1975) and learning performance (Katz, 1980). The effect on the serotonergic system has not been studied in any detail.

\section{Implications}

Future research should attempt to replicate the findings using a lifetime definition of depression in an elderly cohort, and repeating the study in a younger cohort. If they are replicated successfully our findings have a number of implications. First, they provide a second inter-generational cause of depression to complement the genetic contribution and thus they increase the proportion of the variance in vulnerability that can be explained by known risk factors. Second, they introduce a new explanation of the comorbidity between depression and coronary heart disease in adulthood, which otherwise cannot be explained fully by smoking or other lifestyle factors. Third, they suggest an integrative hypothesis of the associations between neuroendocrine abnormalities and depression that has been lacking previously from the psychoneuroendocrinology literature, because many of the identified abnormalities may be programmed during foetal life.

\section{REFERENCES}

Almeida, O. P. \& Almeida, S. A. (1999) Short versions of the Geriatric Depression Scale: a study of their validity for the diagnosis of major depressive episode according to ICD-10 and DSM-IV. International Geriatric Psychiatry, 14, 858-865.

Anda, R., Williamson, D., Jones, D., et al (1993) Depressed affect, hopelessness, and the risk of ischaemic heart disease in a cohort of US adults. Epidemiology, 4, 285-294.

Barker, D. J. P. (1998) Mothers, Babies and Health in Later Life. Edinburgh: Churchill Livingstone.

_, Osmond, C., Winter, P. D., et al (1989) Weight in infancy and death from ischaemic heart disease. Lancet, 2, 577-580.

_ , _ , Rodin, l., et al (1995) Low weight gain in infancy and suicide in adult life. British Medical Journal, 3II, 1203.

Beekman, A. T. F., Deeg, D. J. H., Geerlings, S. W., et al (200I) Emergence and persistence of late life depression: a 3 year follow up of the Longitudinal Ageing Study Amsterdam. Journal of Affective Disorders, 65, $131-138$.

Bergant, A. M., Heim, K., Ulmer, H., et al (1999) Early postnatal depressive mood: associations with obstetric and psychosocial risk factors. Journal of Psychosomatic Research, 46, 391-394.

Bierut, L. J., Heath, A. C., Bucholz, K. K., et al (1999) Major depressive disorder in a community based twin sample. Archives of General Psychiatry, 56, 557-563.

Breslau, N. (1995) Psychiatric sequelae of low birth weight. Epidemiological Reviews, 17, 96-106.

Brown, A. S., Susser, E. S., Lin, S. P., et al (1995)

Increased risk of affective disorder in males after second trimester prenatal exposure to the Dutch Hunger Winter of 1944-45. British Journal of Psychiatry, 166 601-606.

_, van Os, J., Driessens, C., et al (2000) Furthe evidence of relation between prenatal famine and major affective disorder. American Journal of Psychiatry, 157, 190-195.

Cannon, M., Jones, P., Gilvarry, C., et al (1997) Premorbid social functioning in schizophrenia and bipolar disorder: similarities and differences. American Journal of Psychiatry, 154, 1544-1550.

Checkley, S. A., Glass, I. B., Thompson, C., et al (1984) Impairment of the growth hormone response to clonidine in endogenous as compared with reactive depression. Psychological Medicine, 14, 773-778.

Clark, P. M., Hindmarsh, P. C., Shiell, A. W., et al (1996) Size at birth and adrenocortical function in childhood. Clinical Endocrinology, 45, 72I-726.

Davies, P. A. \& Stewart, A. L. (1975) Low birth weight infants: neurological sequelae and later intelligence. British Medical Bulletin, 31, 85-91.

Dinan, T. G. (1998) The physical consequences of depressive illness. British Medical Journal, 318, 826.

Fall, C. H. D., Goggin, P. M., Hawtin, P., et al (1997) Growth in infancy, infant feeding, childhood living conditions, and Helicobacter pylori infection at age 70 . Archives of Diseases in Childhood, 77, 310-314.

, Hindmarsh, P., Dennison, E., et al (1998)

Programming of growth hormone secretion and bone density in elderly men: a hypothesis. Journal of Clinical Endocrinology and Metabolism, 83, 135-139.

Foerster, A., Lewis, S. W., Owen, M. J., et al (1991) Low birth weight and a family history of schizophrenia 
predict poor premorbid functioning in psychosis. Schizophrenia Research, 5, 13-20.

Forsen, T., Eriksson, J. G., Tuomilehto, J., et al (1997) Mothers' weight in pregnancy and coronary heart disease in a cohort of Finnish men. British Medical Journal, 315. 837-840.

Green, B. H., Copeland, J. R. M. \& Dewey, M. E. (1992) Risk factors for depression in elderly people: a prospective study. Acta Psychiatrica Scandinavica, 86, 213-217.

\section{Hippisley-Cox, J., Fielding, K. \& Pringle, M. (1998)} Depression as a risk factor for ischaemic heart disease in men: population based case-control study. British Medical Journal, 316, 1714-1719.

Jones, P. B., Rantakallio, P., Hartikainen, A.-L., et al (1998) Schizophrenia as a long term outcome of pregnancy, delivery and prenatal complications: a 28 year follow up of the 1996 North Finland General Population Birth Cohort. American Journal of Psychiatry, I55, 355-364.

Katz, H. B. (1980) The influence of under-nutrition on learning performance in rodents. Nutrition Abstracts and Reviews. 50, 767-784.

Kendler, K. S., Karkowski, L. M. \& Prescott, C. A. (1999) Causal relationship between stressful life events and the onset of major depression. American Journal of Psychiatry, 156, 837-84I.

Lopez, J. F., Chalmers, D. T., Little, K. Y., et al (1998) Regulation of serotonin ${ }_{\mathrm{la}}$, glucocorticoid and mineralocorticoid receptor in rat and human hippocampus: implications for the neurobiology of depression. Biological Psychiatry, 43, 547-573.

McCance, R. A. \& Widdowson, E. M. (1974) The determinants of growth and form. Proceedings of the Royal Society of London B, 185, I-17.

McWilliam, C., Copeland, J. R. M., Dewey, M. E., et al (1988) The Geriatric Mental State Examination as a case-finding instrument in the community. British Journal of Psychiatry, 152, 205-208.

Morton, N. (1955) The inheritance of human birthweight. Annals of Human Genetics, 20, 123-134.

Murphy, E. (1982) Social origins of depression in old age. British Journal of Psychiatry. 14I, 135-142.

Murphy, B. E. P. (1991) Steroids and depression. Journal of Steroid Biochemistry, 38, 537-559.

National Institutes of Health (1992) NIH consensus conference. Diagnosis and treatment of depression in late life. Journal of the American Medical Association, 268 1018-1024.

Nemeroff, C. B., Widerlov, E., Bisette, G., et al (1984) Elevated concentrations of CSF corticotropin-releasing factor like immuno-reactivity in depressed patients. Science, 226, 1342-1344.

Oomen, H. A. P. C., Schippering, A. J. M. \& Drexhage, H. A. (1996) The prevalence of affective disorders and in particular of a rapid cycling bipolar disorder in patients with abnormal thyroid function tests. Clinical Endocrinology, 45, 215-223.

Osmond, C., Barker, D. J. P., Winter, P. D., et al (1993) Early growth and death from cardiovascular disease in women. British Medical Journal, 307, 1519-1524.

Philips, D. I.W., Barker, D. J. P. \& Osmond, C. (1993) Infant feeding, foetal growth and adult thyroid function Acta Endocrinologica, 129, 134-138.

\section{CLINICAL IMPLICATIONS}

- A non-genetic inter-generational risk factor has been implicated in depression.

- Depression and cardiovascular disease may share a common origin in foetal life.

- The study has shown a gender difference in risk factors for depression.

\section{LIMITATIONS}

- Late-life depression may differ from depression in earlier life and these findings may or may not extrapolate to life-time risk.

- A hybrid of self-rating scale and interview-based diagnosis was used for case definition of current depression.

- Certain social or illness variables, such as dementia, may have remained uncontrolled.

CHRISTOPHER THOMPSON, FRCPsych, HOLLY SYDDALL, MSc, IAN RODIN, MRCPsych, CLIVE OSMOND PhD, DAVID J. P. BARKER, FRS, MRC Environmental Epidemiology Unit and Community Clinical Sciences Research Division, University of Southampton, Southampton

Correspondence: Dr ChristopherThompson, Department of Psychiatry, Royal South Hants Hospital, Brinton's Terrace, Southampton SOI4 OYG, UK

(First received 22 November 2000, final revision 9 May 200I, accepted 17 May 200I)

_ , _ , Fall, C. H. D., et al (1998) Elevated plasma cortisol concentrations; a link between low birth weight and the insulin resistance syndrome? Journal of Clinical Endocrinology and Metabolism, 83, 757-760.

Popkin, M. K., Callies, A. L., Lentz, R. D., et al (1988) Prevalence of major depression, simple phobia, and other psychiatric conditions in patients with long standing type I diabetes mellitus. Archives of General Psychiatry, 45, 64-68.

Poulsen, P., Vaag, A. A., Kyvik, K. O., et al (1997) Low birth weight is associated with NIDDM in discordant monozygotic and dizygotic twin pairs. Diabetologia, 40, $439-446$.

Poulter, N. R., Chang, C. I., MacGregor, A. J., et al (1999) Association between birth weight and adult blood pressure in twins: historical cohort study. British Medical Journal, 319, 1330-1333.

Prince, M. J., Harwood, R. H., Thomas, A., et a (1998) A prospective population based cohort study of the effects of disablement and social milieu on the onse and maintenance of late life depression. The Gospel Oak Project VII. Psychological Medicine, 28, 337-350.

Rifkin, L., Lewis, S., Jones, P., et al (1994) Low birth weight and schizophrenia. British Journal of Psychiatry 165, 357-362.

Rose, G. A. \& Blackburn, H. (1968) Cardiovascular Survey Methods. Geneva: WHO.
Sacker, A., Done, D. J., Crow, T. J., et al (1995)

Antecedents of schizophrenia and affective illness. Obstetric complications. British Journal of Psychiatry, 166 734-741.

Sakkas, P. N., Soldatos, C. R., Bergiannaki, J. D., et a (1998) Growth hormone secretion during sleep in male depressed patients. Progress in Neuropsychopharmacology and Biological Psychiatry, 22, 467-483.

Schule, C., Laakman, G., Baghai, T., et al (1997) European Neuropsychopharmacology, 7, 294-299.

StataCorp (1997) Stata Statistical Software: Release 5.0. College Station, TX: Stata Corporation.

Susser, E., Neugebauer, R., Hoek, H.W., et al (1996) Schizophrenia after prenatal famine: further evidence. Archives of General Psychiatry. 53, 25-31.

Vaillant, G. E. (1998) Natural history of male psychological health. XIV: Relationship of mood disorder to physical health. American Journal of Psychiatry, $\mathbf{1 5 5}$. |84-191.

Winick, M., Rosso, P. \& Brasel, J. A. (1972)

Malnutrition and cellular growth in the brain: existence of critical periods. In Lipids, Malnutrition and the Developing Brain (anonymous), pp. 199-212. New York: Associated Scientific.

World Health Organization (1992) Tenth Revision of the International Classification of Diseases and Related Health Problems (ICD-10). Geneva: WHO. 